\title{
Natural radiation equivalent dose rates assessment in soils and waters of Calabria region, southern Italy
}

\section{GUAGLIARDi ${ }^{1}$, N. RiCCA ${ }^{1}$, E. INFUSINO ${ }^{2}$,} G. CALlegari ${ }^{1}$, T. CALOIERO ${ }^{1}$

${ }^{1}$ National Research Council of Italy - Institute for Agricultural and Forest Systems in the Mediterranean (CNR-ISAFOM), 87036 Rende (CS), Italy

${ }^{2}$ University of Calabria - Department of Environmental and Chemical Engineering (DIATIC), Rende (CS), Italy

In this study, the equivalent dose rate of natural radionuclides $\left(H_{T}\right)$ in 99 spring water and surface soil samples was determined using an alfa, beta and gamma high sensitivity detector up within a Geiger-Muller tube and with an external probe $\mathrm{NaI}$ (Tl). The samples were collected in the Crati basin (southern Italy), and during the samples collection water quality parameters were detected in situ and at the University of Calabria laboratories. Pearson correlation coefficient analysis was applied to identify and clarify the relationships between water physical-chemical properties, soil and water radioactivity. Results show that the mean $H_{T}$ for spring waters is $97.07 \mu \mathrm{Sv} / \mathrm{h}$, with a maximum value of $175 \mu \mathrm{Sv} / \mathrm{h}$ and a minimum of $31 \mu \mathrm{Sv} / \mathrm{h}$. Furthermore, the mean $H_{T}$ for surface soils is $97.92 \mu \mathrm{Sv} / \mathrm{h}$, with a maximum value of $147 \mu \mathrm{Sv} / \mathrm{h}$ and a minimum of 31 $\mu \mathrm{Sv} / \mathrm{h}$, thus evidencing higher mean $H_{T}$ values than worldwide ones reported by previous literature. Low correlation coefficients were detected between the water $H_{T}$ and conductivity and $\mathrm{pH}$, with $\mathrm{r}$ values equal to -0.23 and -0.36 , respectively. On the contrary, a reasonable correlation was found between $H_{T}$ in spring water and in soil. This relationship is associated with plutonic and metamorphic crystalline rocks of the Sila Massif and of the Coastal Chain, upon which the Crati basin soils are imposed. The results from this survey for the $H_{T}$ assessment provide an extensive evaluation of the background exposure levels in the studied area. 